\title{
A Transient Wellbore Trajectory Prediction Model using Transfer Matrix Method
}

\author{
Hongxing $\mathrm{Li}^{1}$, Xingang $\mathrm{Wang}^{2}$, Xuelong $\mathrm{Bai}^{3}$, Yan Zhang ${ }^{4 *}$, Zixuan $\mathrm{Li}^{5}$ \\ ${ }^{1,2,3}$ China Oilfield Services \\ ${ }^{4,5}$ Yangtze University
}

*Corresponding Author: Yan Zhang, Yangtze University

\begin{abstract}
Wellbore trajectoryprediction is one of the most important topics in the drilling engineering field. To predict the wellbore trajectory accurately, a good understanding of the bottom hole assembly (BHA) mechanics is essential. In this study, a Transfer Matrix method was used to model the BHA in $2 D$ static conditions. The bit and formation anisotropy are also considered in the model. By using the Transfer Matrix principle, wellbore trajectory in the transient condition(from the initial conditions to the final equilibrium conditions) can be predicted after finding the direction of the wellbore at the initial conditions.Results shown that the Transfer Matrix method is an effective way to calculate thedynamic BHA conditions and prediction transient wellbore trajectory during drilling.
\end{abstract}

Keywords: Wellbore trajectory, Bottom Hole Assembly; Mechanical Model; Transfer Matrix

\section{Introduction}

With the development of oil and gas resources, more horizontal wells, extended reach wells and other complex structure wells are drilled today ${ }^{1}$. To reduce the drilling cost, a comprehensive modeling of the factors affecting a wellbore's path (e. g; inclination angle, Bottom Hole Assembly, etc.), is needed to drill as economically as possible. In addition, the drilling cost also can be reduced significantly while the wellbore trajectory being predicted for various conditions and BHAs. It has been found that the factors affect wellbore trajectory, mainly consist two categories: BHA configuration and drilling conditions. Therefore, choosing the corresponding Bottom Hole Assembly (BHA) for drilling is absolutely critical. Furthermore, it is necessary to study the initial conditions of the drill string and the bit/rock interactions before predicting the wellbore trajectory.

In 1953, Lubinski and Woods ${ }^{2}$ showed the way of modeling a slick BHA in a straight wellbore. They developed an analytical method to calculate the side force at the bit and concluded that even in an isotropicsystemdrill bit cannot drill in a vertical path unless a very low Wight on Bit (WOB) is used. Then Murphy and Cheatham ${ }^{3}$ extended the model to curved holes of known and constant curvature. After that, Fischer ${ }^{4}$ presented an analysis of the static behavior of a BHA in two dimensional curved wellbores.In his work, the finite differences method was developed to solve the differential equationsof bending of the drill collars. Almost at the same time, Millheim et al. ${ }^{5}$ Applied the finite element method to solve for the shape of drill collars that provide the minimum of potential energy. Based on the previous work of BHA behavior research, Callas ${ }^{6}$ developed a model for predicting borehole trajectories in two dimensional curved holes. But the solutions were considered only for the approximate bending equation, with up to four arbitrarily placed stabilizers. Then Cheathman ${ }^{7}$ established a theoretical model for directional drilling tendency and discussed both bitisotropic/anisotropic and formation isotropic/anisotropic system. In 1984, Sind linger ${ }^{8}$ proposed a method to predict the trajectory of a borehole by drilling along the resultant force angle. The resultant force angle is found by solving the elastic beam of the BHA. As a M.S. thesis work, Suchato ${ }^{9}$ focused on the transient wellbore trajectory. This work can be used to determine the drilling direction when dual anisotropy (formation and bit anisotropy) indexes are considered. As a comparison, $\mathrm{Ho}^{10}$ introduced another rock-bit interation model for the simultaneous effects of rock/bit anisotropies on the drilling condition. In his work, a 3D analysis was stated to be essential for properly prediction of the drilling direction because a 2D analysis ignores the walking tendency. For this reason, Larson and 
Azar ${ }^{11}$ and Neubert and Heisig ${ }^{12}$ presented two new models for well bore trajectory prediction. Recently, there some new research works about the wellbore trajectory prediction. Henky Chan ${ }^{13}$ found a new approach to predict transient trajectory by found the side force at the bit first and then link the initial condition to a final condition. Another work, Gaynor and $\mathrm{Chen}^{14}$ mainly focused on side cutting and its influence on drilling direction. In the work they tried to investigate that whether long-gauge bits can be used to drill directional well. Neubert and Heisig ${ }^{15}$ made a mathematical model for the mechanical behavior of BHAs under various downhole conditions. Although it didn't mentioned any wellbore trajectory results, the model was suggested may be used to find a direction tendency.

As the BHA configuration is one of the factors that affect the wellbore trajectory, the prediction of wellbore trajectory is particularly important for complex BHA. However, the side force calculation by analytical method has not been introduced from the above literatures. Also among the numerical methods, in case of a "very complex BHAs", they show some instability problems. In this study, the side force at the bit for complex BHA is modeled by using the "Transfer Matrix" theory. After getting the side force and weight on bit(WOB), an anticipated bit direction will be evaluated with considering the drilling conditions and finally the wellbore trajectory prediction will be attempted.

\section{BHA Mechanical Model}

Drill collars in the wellbores act like a beam with a compressive axial load which is called Weight on Bit (WOB). They can be modeled as flexible elastic beams between two points: bit and tangency point. By definition, the distance between the bitand such a point is called tangency length. Figure 1 shows the governing system of coordinates for the BHA.

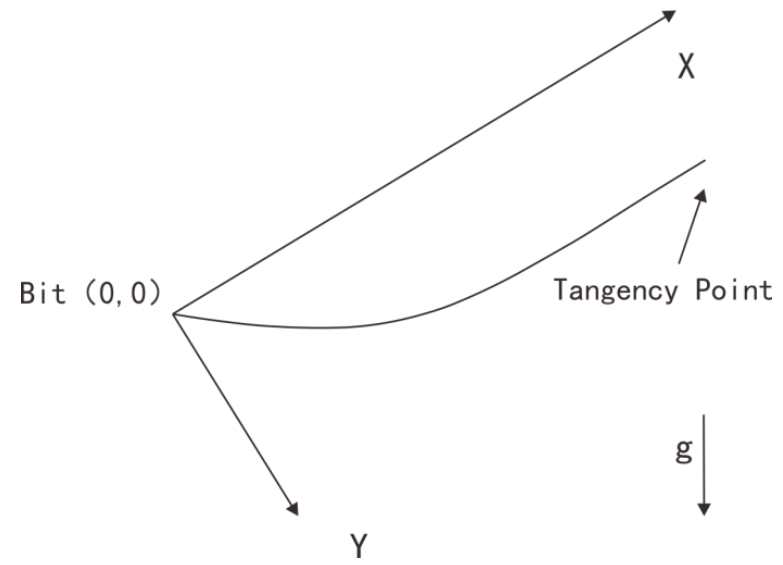

Figure1. Governing System of Coordinates for the BHA

Use the Elastic Beam Theory, the BHA can be modeled as a beam in a 2D static condition. For the slick BHA which consists of the drill bit and only one drill collar, it acts like a beam with aconstantan axial load, WOB. Utilizing the Elastic Theory from the solid mechanics, we assume the weight on bit (WOB) is much greater than the unit of the drilling collars. After finding the shear force, the governing differential equation of the BHA beam can be written as:

$\mathrm{EI} \frac{d^{3} Y}{d X^{3}}+W O B \frac{d Y}{d X}=H_{0}+P X \sin \alpha$

Following the dimensionless format introduced by Murphy and Cheatham ${ }^{3}$, Equation (1) can be derived as:

$y^{\prime \prime \prime}(x)+y^{\prime}(x)=h_{0}+x$

For a slick BHA, it is assumed to be supported by two points: the bit and the tangency point under a constant compressive load. Then the boundary conditions can be written as:

At the bit $(X=x=0)$ :

$\mathrm{Y}=0 \Rightarrow \mathrm{y}=0$ (No deflection at the bit)

EI $\frac{d^{2} Y}{d X^{2}}=0 \Rightarrow \frac{d^{2} y}{d x^{2}}=0$ (No moment at the bit)

At the tangency point $(\mathrm{X}=\mathrm{L}$ and $\mathrm{x}=1)$ : 
$\mathrm{Y}=\mathrm{R} \Rightarrow \mathrm{y}=\mathrm{r}=\mathrm{c}($ Deflection is equal to radial clearance $)$

$\frac{d Y}{d X}=0 \Rightarrow \frac{d y}{d x}=0($ Slope $=0)$

$\mathrm{EI} \frac{d^{2} Y}{d X^{2}}=0 \Rightarrow \frac{d^{2} y}{d x^{2}}=0$

Where $\mathrm{R}=$ Radial clearance or deflection at the tangency point and $\mathrm{r}=\mathrm{c}=$ Dimensionless radial clearance as shown in Figure 2, and the radial clearance can be calculated from the hole size and drill collar's OD as:

$\mathrm{R}=\mathrm{C}=\frac{\text { HoleSize }-O D}{2}$

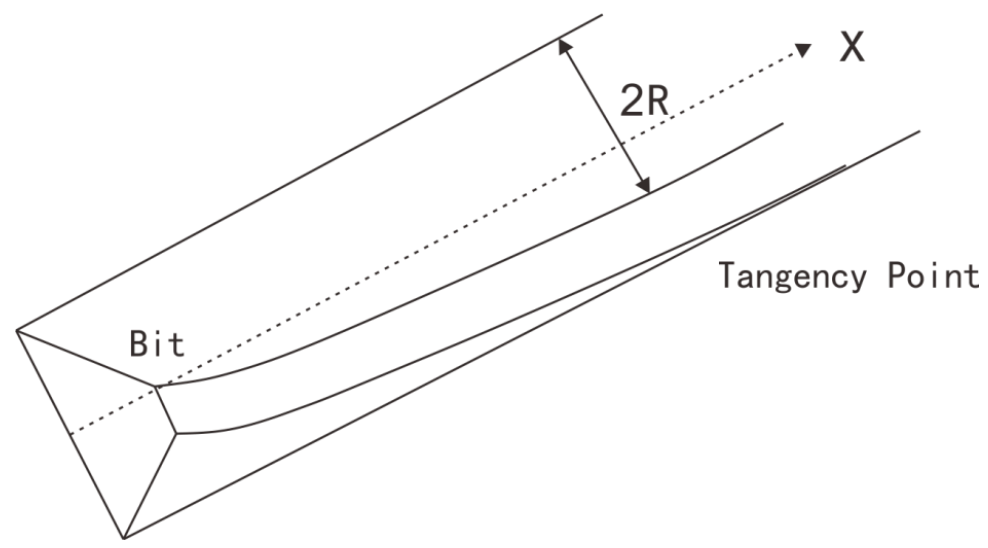

Figure2. Radial Clearance of the Wellbore

With the boundary conditions listed above, Equation (2) can be solved to acquire he dimensionless side force and the dimensionless tangency length as:

$h_{0}=\tan \left(\frac{l}{2}\right)-l$

$\mathrm{r}=\mathrm{c}=l \tan \left(\frac{l}{2}\right)-\frac{l^{2}}{2}$

Then using the scaling factors dimensional values will be found (valid for $0<\mathrm{x} \leq 1$ ), and other values, e.g. tilt angle, can be calculated after finding the side force and tangency length.

\section{Transfer Matrix Theory}

A complex BHA can be modeled as multiple beams. At the bit, the above-mentioned boundaries are valid as well as at the tangency point. However, it is not that simple to find an analytical solution for

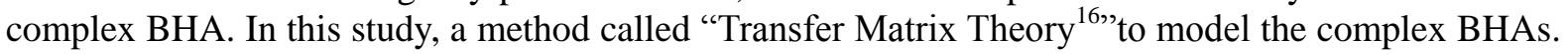
Transfer matrix is a $5 \times 5$ matrixand links the beginning of the element (in a multi-element BHA) to the end of that element. If the state variables (deflection, slope, moment and shear force) are known at the bit, the Transfer matrix will take these values and transfers them to the end of the BHA. As shown by Equation (11):

$\left[\begin{array}{c}y \\ y^{\prime} \\ e y^{\prime \prime} \\ h \\ 1\end{array}\right]_{\text {End }}=\left[\begin{array}{lllll}a_{11} & a_{12} & a_{13} & a_{14} & a_{15} \\ a_{21} & a_{22} & a_{23} & a_{24} & a_{25} \\ a_{31} & a_{32} & a_{33} & a_{34} & a_{35} \\ a_{41} & a_{42} & a_{43} & a_{44} & a_{45} \\ a_{52} & a_{52} & a_{53} & a_{54} & a_{55}\end{array}\right]\left[\begin{array}{c}y \\ y^{\prime} \\ e y^{\prime \prime} \\ h \\ 1\end{array}\right]_{\text {Initial }}$

Where $y, y^{\prime}$, e $y^{\prime \prime}, \mathrm{h}$ respectively represent the deflection, slope, moment and side force along the BHA. The first row transferthe deflection, the second row transfer the moment while, the third row represents the moment transformation. The forth row is responsible for the side force transformation along the BHA and the last row is determined by the "loading conditions". Transfer Matrixes can be categorized into two sub categories ${ }^{16}$ : field matrixes $(\mathrm{U})$ and point matrixes (P). For complex BHA system, the drill collars that has a known physical length can be modeled as field matrixes while the stabilizers that do not have a physical length are usually modeled as point matrixes.

Each element in the BHA, such as stabilizers, ben subs, can be modeled by determining the length of the last element and then constructing the overall matrix. After that, the side force and the slope are 
calculated and they examined by another equation. For example, a bent sub matrix equation can be derived as:

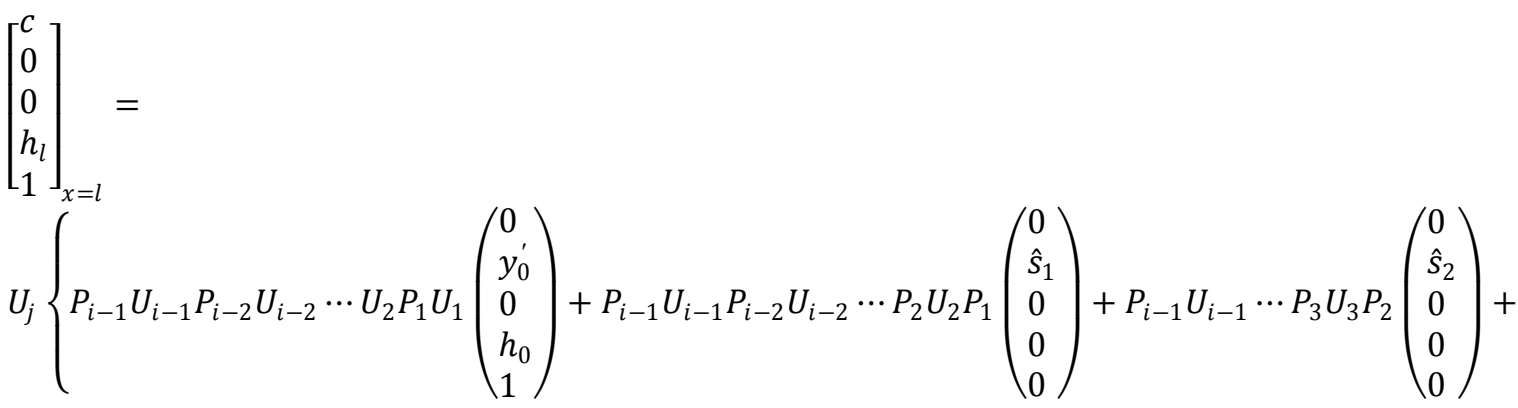

$\cdots+P i^{-1}-1 i^{-}-1 P i-20 s i-2000+P i-10 s i-i 000$

(12)

Where $\mathrm{c}$ is the radial clearance at the tangency point; $h_{l}$ is the shear Force at the tangency point; $\hat{s}_{i}$ is the dimensionless known bent sub angle. Now we define $A=U_{i} P_{i-1} U_{i-1} P_{i-2} U_{i-2} \cdots U_{2} P_{1} U_{1}$ as the overall matrix which accounts for all the elements andstabilizers (touching/non-touching) in the BHA system. Then another vector, "B", which accounts for the bent subs can be defined as:

$$
B=U_{i}\left(P_{i-1} \cdot U_{i-1} P_{i-2} U_{i-2} \cdots P_{2} U_{2} P_{1}\left(\begin{array}{l}
0 \\
\hat{s}_{1} \\
0 \\
0 \\
0
\end{array}\right)+P_{i-1} U_{i-1} \cdots P_{3} U_{3} P_{2}\left(\begin{array}{l}
0 \\
\hat{s}_{2} \\
0 \\
0 \\
0
\end{array}\right)+P_{i-1} U_{i-1} P_{i-2}\left(\begin{array}{l}
0 \\
\hat{s}_{i-2} \\
0 \\
0 \\
0
\end{array}\right)+\right.
$$

$P i^{-10}-10 \mathrm{i}-\mathrm{i000}$

(13)

In case of unlimited elements, stabilizers and the bent subs, the length of the last element should be estimated initially. Therefore, matrix " $A$ " (which takesinto account the elements and the stabilizers) and vector B (which takes into account bent subs) can be constructed as:

$$
\left(\begin{array}{l}
c \\
0 \\
0 \\
h_{l} \\
1
\end{array}\right)_{\text {End }}=\left[\begin{array}{lllll}
a_{11} & a_{12} & a_{13} & a_{14} & a_{15} \\
a_{21} & a_{22} & a_{23} & a_{24} & a_{25} \\
a_{31} & a_{32} & a_{33} & a_{34} & a_{35} \\
a_{41} & a_{42} & a_{43} & a_{44} & a_{45} \\
a_{52} & a_{52} & a_{53} & a_{54} & a_{55}
\end{array}\right]\left(\begin{array}{l}
0 \\
y_{0}^{\prime} \\
0 \\
h_{0} \\
1
\end{array}\right)_{\text {Intital }}+\left(\begin{array}{l}
b_{1} \\
b_{2} \\
b_{3} \\
b_{4} \\
b_{5}
\end{array}\right)
$$

For the complex BHA case, the side force and tilt angle calculations can be categorized in two groups:

A. No contact point along the BHA

From Equation (14), at the tangency point we can write two equations similar to equation (14) and (15). By solving the two equations for the $h_{0}$ (dimensionless side force at the bit) and $y_{0}$ '(slope at the bit that gives the tilt angle) yields the following equations:

$y_{0}^{\prime}=\frac{a_{24} a_{35}-a_{25} a_{34}+a_{24} b_{31}-a_{34} b_{21}}{\nabla}$

$h_{0}=\frac{a_{25} a_{32}-a_{22} a_{35}+a_{32} b_{21}-a_{22} b_{31}}{\nabla}$

Where $\nabla=a_{22} a_{34}-a_{24} a_{32}$. Also, if the correct value for the tangency length is determined, theequation $a_{12} y_{0}{ }^{\prime}+a_{14} h_{0}+a_{15}+b_{11}-c=0$ must be satisfied.

B. There is a contact along the BHA which can be caused by the stabilizers or the bent subs

In this case, after guess the length of the last element, the dimensionless side force and the dimensionless slope at the bit can be solved as:

$h_{0}=\frac{a_{35} u_{12}^{1}-a_{32} u_{15}^{1}+u_{12}^{1} b_{31} \pm a_{32} c_{s t, 1}}{\nabla}$ 
$y_{0}^{\prime}=\frac{a_{34} u_{15}^{1}-a_{35} u_{14}^{1}-u_{14}^{1} b_{31} \pm a_{34} c_{s t, 1}}{\nabla}$

Where $\nabla=a_{32} u_{14}^{1}-a_{34} u_{12}^{1}$. In the same fashion, if the guessed value is chosen correctly, the equation $a_{22} y_{0}{ }^{\prime}+a_{24} h_{0}+a_{25}+b_{21}=0$ must be satisfied.

For all the above cases, the procedure is very similar. Initially we guess a value for the last element's length. After calculating the side force and slope at the bit, the last equation must be satisfied. Otherwise, the length of the last element increases (that gives tangency length) until the desired answers obtained.

\section{Verification of the Mechanical Model}

To verify the mechanical model, a practical BHA configuration is selected and the prediction results are discussed.

This BHA consists of seven elements and three stabilizers. The stabilizers are located after the first element, fifth and sixth elements, respectively. Also, a positive-angle bent sub is found after the third element. For this complex BHA the initial inclination angle is 45 degree and there is $133447 \mathrm{~N}$ on the bit (WOB). Table 1 lists the hole parameters and Table 2 lists BHA properties. The results obtained by the simulator are given in the table 3 .

Table1. Hole Parameters

\begin{tabular}{|c|c|}
\hline Number of elements: & $\mathbf{7}$ \\
\hline Hole Diameter: & $31122 \mathrm{~m}$ \\
\hline Inclination angle: & 45.00 degree \\
\hline Weight on the Bit: & $133447 \mathrm{~N}$ \\
\hline Mud Density: & 10.00 Pounds/Gallon \\
\hline
\end{tabular}

Table2. BHA Physical Properties

\begin{tabular}{|c|c|c|c|c|c|c|}
\hline Unit & OD $(\mathrm{mm})$ & ID $(\mathrm{mm})$ & Length $(\mathrm{m})$ & Unit Weight $(\mathrm{kg} / \mathrm{m})$ & Stabilizer OD $(\mathrm{mm})$ & Sub $(\mathrm{deg})$ \\
\hline 1 & 196.9 & 151.3 & 1.10 & 204.09 & 308.0 & 0.00 \\
\hline 2 & 196.9 & 151.3 & 0.84 & 204.09 & 196.9 & 0.00 \\
\hline 3 & 196.9 & 151.3 & 1.01 & 204.09 & 196.9 & +1.00 \\
\hline 4 & 196.9 & 151.3 & 4.37 & 204.09 & 196.9 & 0.00 \\
\hline 5 & 203.2 & 71.4 & 5.33 & 221.70 & 309.5 & 0.00 \\
\hline 6 & 203.2 & 71.4 & 10.67 & 221.70 & 309.5 & 0.00 \\
\hline 7 & 203.2 & 71.4 & - & 221.70 & 203.2 & 0.00 \\
\hline
\end{tabular}

Table3. Results

\begin{tabular}{|c|c|}
\hline Tangency Length: & $36.84 \mathrm{~m}$ \\
\hline Side Force at the bit: & $44323.9 \mathrm{~N}$ \\
\hline Tilt Angle: & 0.031 Degree \\
\hline Side Force at the stabilizer (1): & $-56660 \mathrm{~N}$ \\
\hline Side Force at the stabilizer (2): & $-7584 \mathrm{~N}$ \\
\hline Side Force at the stabilizer (3): & $-20397 \mathrm{~N}$ \\
\hline
\end{tabular}

Then the side forces at the bit, stabilizer (1), stabilizer (2) and stabilizer (3) obtained by thenew model, were compared to the programs written by Miska and Chen ${ }^{13}$. All the inputs as shown in Table 4and comparison of results is shown in Table 5.

Table4. Inputs information for the different complex BHA cases

\begin{tabular}{|c|c|}
\hline & Data \\
\hline Case 1 & $\alpha=10 \mathrm{deg} ., \mathrm{BSA}=1.00 \mathrm{deg}$. \\
\hline Case 2 & $\alpha=45 \mathrm{deg} ., \mathrm{BSA}=1.00 \mathrm{deg}$. \\
\hline Case 3 & $\alpha=90 \mathrm{deg} ., \mathrm{BSA}=1.00 \mathrm{deg}$. \\
\hline Case 4 & $\alpha=10 \mathrm{deg} ., \mathrm{BSA}=-1.00 \mathrm{deg}$. \\
\hline Case 5 & $\alpha=45 \mathrm{deg} ., \mathrm{BSA}=-1.00 \mathrm{deg}$. \\
\hline Case 6 & $\alpha=90 \mathrm{deg} ., \mathrm{BSA}=-1.00 \mathrm{deg}$. \\
\hline
\end{tabular}


Table5. Comparison of the side forces by different researchers

\begin{tabular}{|c|c|c|c|c|c|c|c|c|c|c|c|c|}
\hline & \multicolumn{12}{|c|}{ Side forces at different position(N) } \\
\hline & \multicolumn{3}{|c|}{ Bit } & \multicolumn{3}{|c|}{ stabilizer $(1)$} & \multicolumn{3}{|c|}{ stabilizer (2) } & \multicolumn{3}{|c|}{ stabilizer (3) } \\
\hline & Simulator & Chen & Miska & Simulator & Chen & Miska & Simulator & Chen & Miska & Simulator & Chen & Miska \\
\hline $\begin{array}{c}\text { Case } \\
1\end{array}$ & 34598 & 35737 & 34158 & $\begin{array}{c}- \\
39643 \\
\end{array}$ & $\begin{array}{c}- \\
41324\end{array}$ & $\begin{array}{c}- \\
38926\end{array}$ & 2842 & 1788 & 2895 & $\begin{array}{c}- \\
7610\end{array}$ & $\begin{array}{c}- \\
7290\end{array}$ & $\begin{array}{c}- \\
7553\end{array}$ \\
\hline $\begin{array}{c}\text { Case } \\
2\end{array}$ & 39967 & 47165 & 40443 & $\begin{array}{c}- \\
48503\end{array}$ & $\begin{array}{c}- \\
58414\end{array}$ & $\begin{array}{c}- \\
49019\end{array}$ & $\begin{array}{c}- \\
6695\end{array}$ & $\begin{array}{c}- \\
10039\end{array}$ & $\begin{array}{c}- \\
5600\end{array}$ & $\begin{array}{c}- \\
20795\end{array}$ & -20003 & $\begin{array}{c}- \\
20839\end{array}$ \\
\hline $\begin{array}{c}\text { Case } \\
3 \\
\end{array}$ & 42685 & 52849 & 43063 & $\begin{array}{c}- \\
53067\end{array}$ & $\begin{array}{c}- \\
67061 \\
\end{array}$ & $\begin{array}{c}- \\
53512 \\
\end{array}$ & $\begin{array}{c}- \\
12272 \\
\end{array}$ & $\begin{array}{c}- \\
17010\end{array}$ & -10853 & $\begin{array}{c}- \\
27200 \\
\end{array}$ & -26018 & $\begin{array}{c}- \\
27237 \\
\end{array}$ \\
\hline $\begin{array}{c}\text { Case } \\
4 \\
\end{array}$ & $\begin{array}{c}- \\
35795 \\
\end{array}$ & -26511 & $\begin{array}{c}- \\
26182 \\
\end{array}$ & 38958 & 27788 & 27090 & $\begin{array}{c}- \\
8122 \\
\end{array}$ & $\begin{array}{c}- \\
6303 \\
\end{array}$ & -36791 & $\begin{array}{c}- \\
2918 \\
\end{array}$ & $\begin{array}{c}- \\
5881 \\
\end{array}$ & $\begin{array}{c}- \\
6566 \\
\end{array}$ \\
\hline $\begin{array}{c}\text { Case } \\
5 \\
\end{array}$ & $\begin{array}{c}- \\
30515 \\
\end{array}$ & -15796 & $\begin{array}{c}- \\
20733 \\
\end{array}$ & 30217 & 11552 & 18064 & $\begin{array}{c}- \\
17793 \\
\end{array}$ & $\begin{array}{c}- \\
18469 \\
\end{array}$ & -12535 & $\begin{array}{c}- \\
14724 \\
\end{array}$ & -18198 & $\begin{array}{c}- \\
19594 \\
\end{array}$ \\
\hline $\begin{array}{c}\text { Case } \\
6 \\
\end{array}$ & $\begin{array}{c}- \\
27824 \\
\end{array}$ & -10129 & $\begin{array}{c}- \\
18149 \\
\end{array}$ & 25693 & 2927 & 13607 & $\begin{array}{c}- \\
23393 \\
\end{array}$ & $\begin{array}{c}- \\
25466 \\
\end{array}$ & -17802 & $\begin{array}{c}- \\
20675 \\
\end{array}$ & -24145 & $\begin{array}{c}- \\
25955 \\
\end{array}$ \\
\hline
\end{tabular}

As shown in Table 5, assuming that Miska's solutions are correct, the new modelgives reasonable results for the Cases 1-3. For these cases, Chen's results are slightly different. However, for cases 4-6 (when there is a minus bent sub angle in the system) Miska's and Chen's solutions agree well, especially for small hole inclination angle. This comparison also can indicate that the model may result in a different solution from the correct one if there is bentsub with the minus angle.

\section{Implementation of the Model with Static Condition Plots}

\subsection{Deflection Analysis Along BHA}

The following plots are obtained by simulating BHA shown in the previous section. The deflection at the bit is zero and at the tangency length-where the BHA touches the wellbore-the deflection is equal to the wellbore clearance. Figure3shows how the deflection varies from the bit to the tangency point. Also, atall the touching points, the deflections are known.

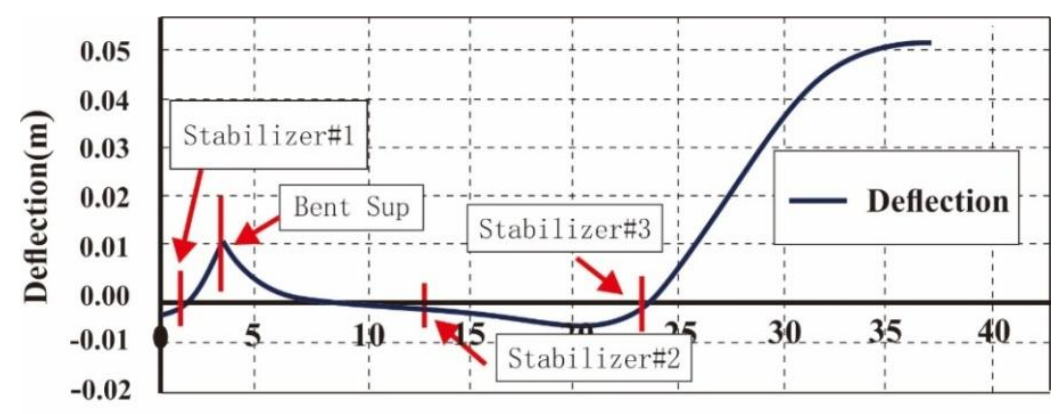

\section{Distance from Bit(m)}

Figure3. Deflection vs. Distance from Bit

The slope of the drill string shows the rate of deflection along the BHA. At the bit, the tiltangle represents the slope. At the tangency point, the slope is zero as the BHA touches the wellbore. Also figure 4, shows that the slope changes before and after the bent sub is equal to1.0 as an input for bent sub angle.

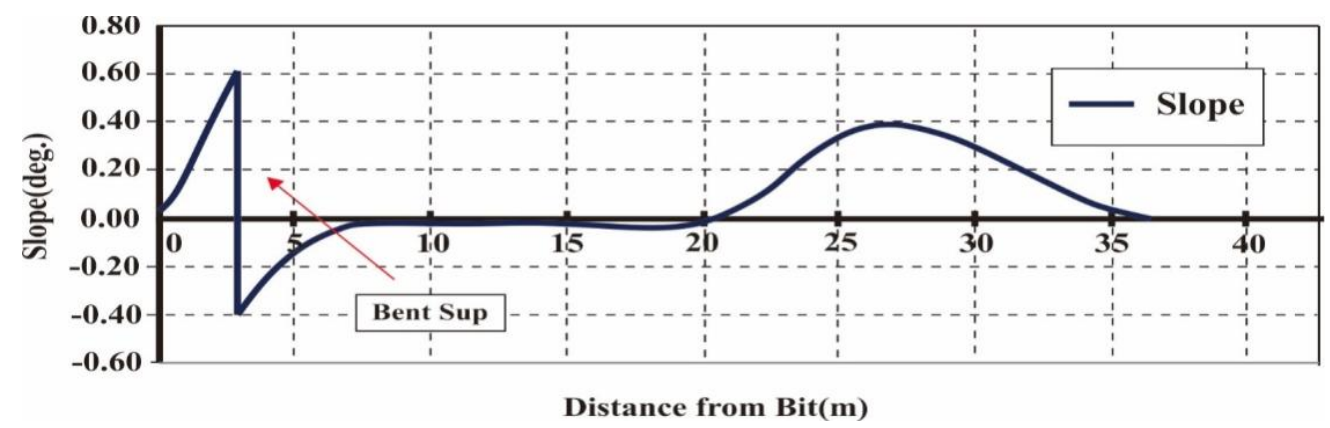

Figure4. Slope vs. Distance from Bit 
The bending moment along the BHA is shown in Figure 5, it is necessary in order to calculate the bending stress. Knowing the moment enables us to calculate the bending stress and select the best possible drill collars.

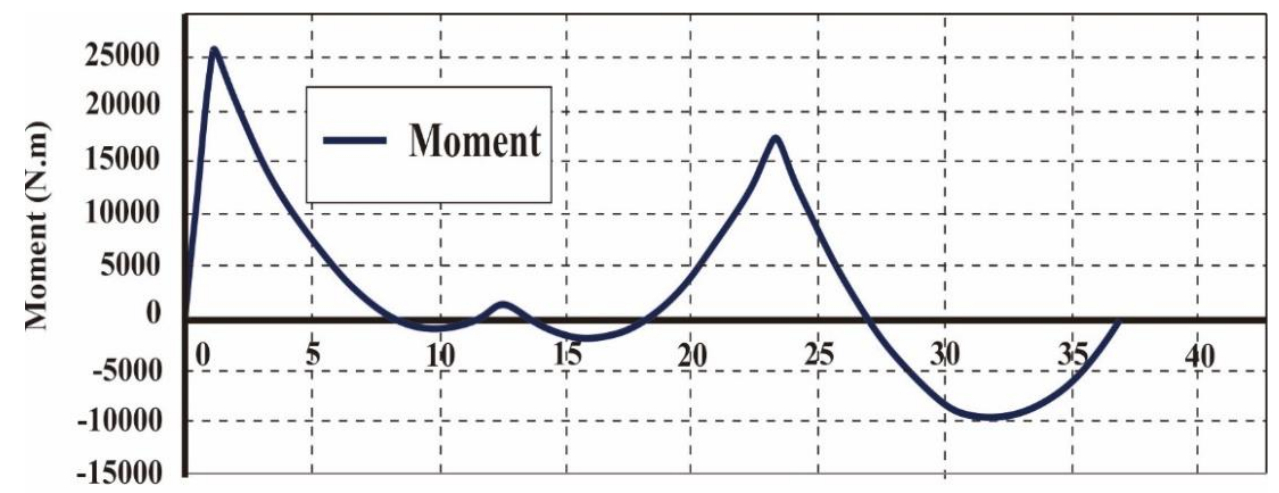

Distance from Bit(m)

Figure5. Bending Moments vs. Distance from Bit

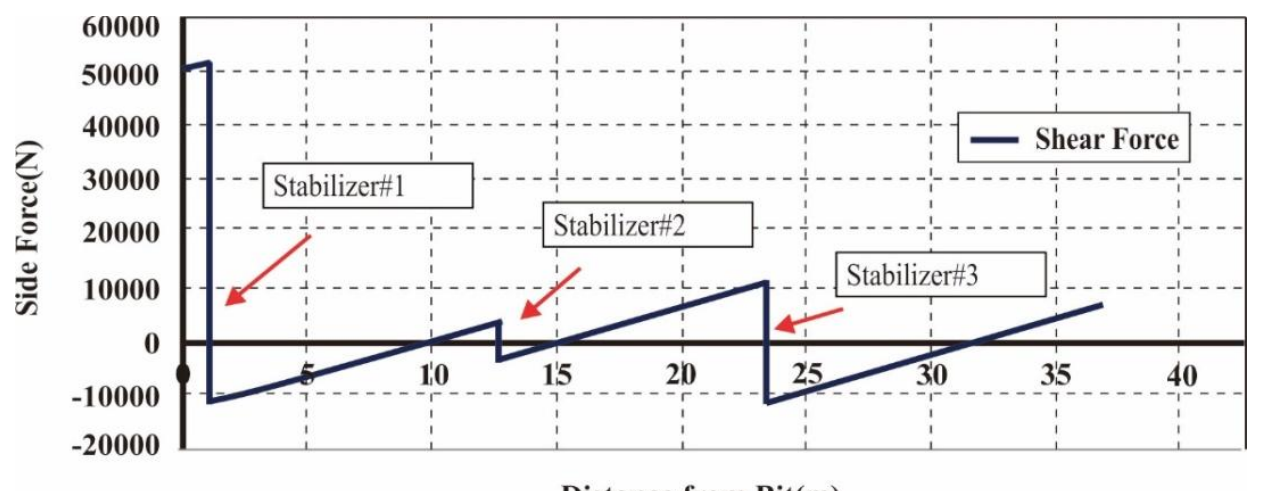

Figure6. Side Force vs. Distance from Bit

Finally, having the side force along the BHA is essential, too. The shear force allows the calculation of the shear stress and the side forces at the touching points. Figure 6 shows that, the touching points, stabilizers in this case, change the side force before and after each one of them. These new side forces are introduced to the system because of the stabilizers and they are marked in Figure 6.

\subsection{Side Force at the Bit}

\subsubsection{The Effects of WOB on the Side Force at the Bit}

Increasing the WOB will increase the building tendency; this increase depends on theBHA configuration, too. For the slick BHA, increasing the WOB may result in a noticeablechange at the bit; however, for a complex BHA, especially when stabilizers are included, thischange may not be felt at the bit. In our case, increasing WOB by 44482 Nslightly increases the side force by approximately 4448Nas seen in Figure 7.

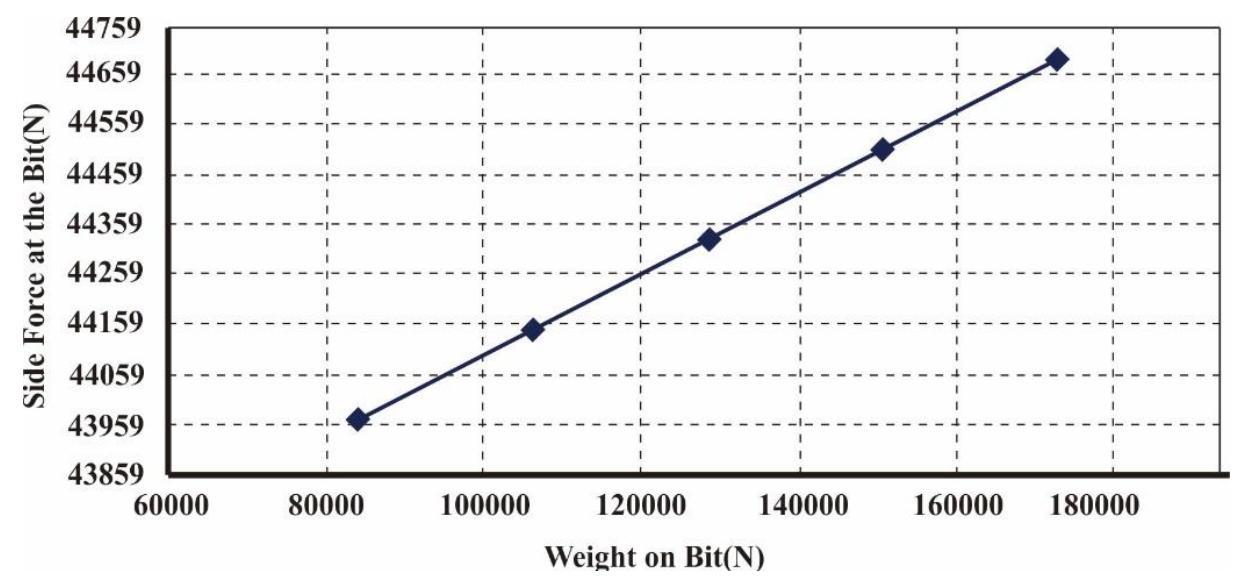

Figure7. Effect of WOB on the Side Force at the Bit 


\subsubsection{The Effect of Hole Size on the Side Force at the Bit}

Increasing the wellbore clearance has a great effect on the side force at the bit. In ourcase, increasing a wellbore clearance by $0.5 \%(0.0127 \mathrm{~m})$ decreases the side force by approximately $13345 \mathrm{~N}$.

In addition, although the effect of the clearance is noticeable at the bit, as we move further along the BHA this effect becomes smaller. The effect of the wellbore clearance forthe discussed BHA is shown in Figure 8.

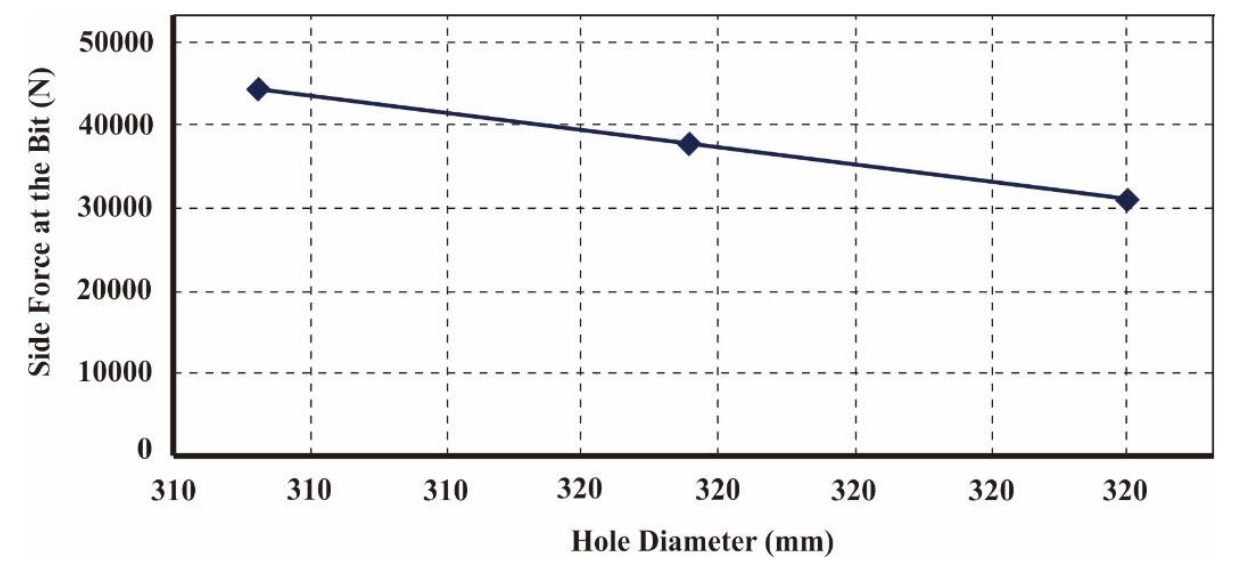

Figure8. Effect of Wellbore Clarence on the Side Force at the Bit

\subsubsection{The Effects of the Bent Sub Angle on the Side Force at the Bit}

Bent sub angle is a controlling factor to obtain the desired side force at the bit. As ageneral rule, increasing the bent sub angle will increase the side force and the building tendency as shown in Figure 9 .

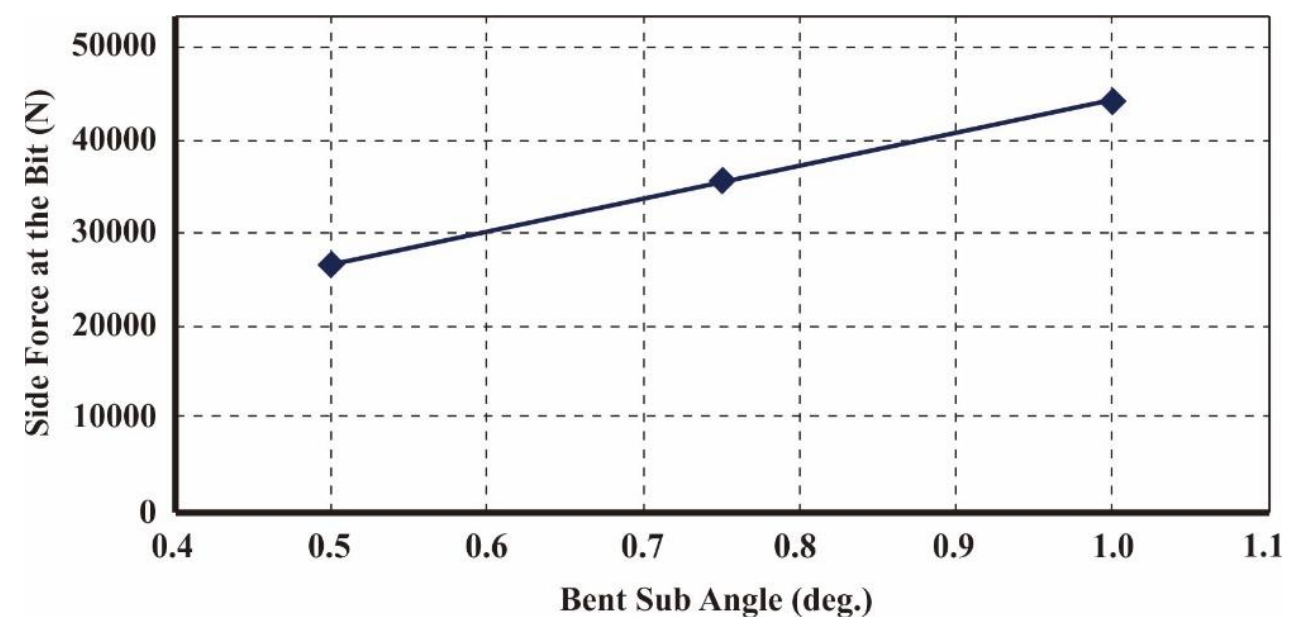

Figure9. Effect of Bent Sub Angle on the Side Force at the Bit

\section{Conclusion}

In this study it is desired to calculate side force at the bit for a complex BHA. To achievethat, a numerical "Transfer Matrix" theory was used. With the side force one can re-calculate the resultant fore and its direction, and finally the transient wellbore trajectory can be predicted. Through this study, the following conclusions and results were found:

- Transfer Matrix method is an effective way to calculate the static values for thecomplex BHA in 2D;

- The closer the stabilizers are to the bit, there will be a greater side force at the bit;

- Increasing WOB will increase the building tendency;

- A larger wellbore diameter will increase the dropping tendency.

ACKNOWLEDGEMENT

The authors would like to thank the China Offshore Service Limited for the financial support of this research (Contract Number: G1817A-A14G120). 


\section{REFERENCES}

[1] Kootiani RC. Investigation of a powerful tool for the development of thinly bedded carbonate reservoirs. INTERNATIONAL JOURNAL OF ENGINEERING. 2014; 27(12):1945-1952.

[2] Lubinski A, Woods H. Factors affecting the angle of inclination and dog-legging in rotary bore holes. Paper presented at: Drilling and Production Practice, 1953.

[3] Murphey C, Cheatham Jr J. Hole deviation and drill string behavior. Society of Petroleum Engineers Journal. 1966; 6(01):44-54.

[4] Fischer FJ. Analysis of drill strings in curved boreholes. Paper presented at: Fall Meeting of the Society of Petroleum Engineers of AIME, 1974.

[5] Millheim K, Jordan S, Ritter C. Bottom-hole assembly analysis using the finite-element method. Journal of petroleum Technology. 1978; 30(02):265-274.

[6] Callas NP. Predicting borehole trajectories. Oil Gas J.;(United States). 1981; 79(34).

[7] Cheatham Jr J, Ho C. A theoretical model for directional drilling tendency of a drill bit in anisotropic rock. 1981.

[8] Sind linger J. Optimizing drilling parameters for directionally drilled holes, New Mexico Institute of Mining and Technology; 1984.

[9] Suchato P. Description of the initial part of transient borehole trajectory behavior in two-dimensions: New Mexico Institute of Mining and Technology, Socorro, NM; 1985.

[10] Ho H. Prediction of drilling trajectory in directional wells via a new rock-bit interaction model. Paper presented at: SPE Annual Technical Conference and Exhibition, 1987.

[11] Larson PA, Azar J. Three-dimensional, quasi-static, drill ahead BHA model for wellbore trajectory prediction and control. 1991.

[12] Neubert M, Heisig G. Advanced trajectory simulation of directional wellbores, 1997.

[13] Chen H, Miska S, Mitchell R. Prediction of transient wellbore trajectory under anisotropic drilling conditions. Wiertnictwo, Nafta, Gaz. 2003;20(2):317-329.

[14] Gaynor T, Chen DC. Is Side-Cutting Really Necessary for Steerable Bits? Paper presented at: SPE Annual Technical Conference and Exhibition, 2004.

[15] Neubert M, Heisig G, Forstner I, Mounzer F. Verification of an Advanced BHA Analysis Model With Downhole Bending Moment Measurements. Paper presented at: SPE Asia Pacific Oil and Gas Conference and Exhibition, 2005.

[16] Pilkey WD, Pilkey OH. Mechanics of Solids: ROBERT E. KRIEGER PUBLISHING COMPANY; 1986.

[17] Aadnoy B, Cooper I, Miska S, Mitchell RF, Payne ML. Advanced drilling and well technology: SPE; 2009

Citation: Yan Zhang, et.al, (2019). "A Transient Wellbore Trajectory Prediction Model using Transfer Matrix Method”, International Journal of Petroleum and Petrochemical Engineering (IJPPE), 5(3), pp.52-60, DOI: http://dx.doi.org/10.20431/2454-7980.0503004

Copyright: (C) 2019 Authors. This is an open-access article distributed under the terms of the Creative Commons Attribution License, which permits unrestricted use, distribution, and reproduction in any medium, provided the original author and source are credited 